\title{
Idosos em instituições de longa permanência:
}

\author{
falando de cuidado
}

Adriana Valéria da Silva Freitas ${ }^{1}$

Ceci Vilar Noronha ${ }^{2}$

FREITAS, A.V.S.; NORONHA, C.V. Elderly people in long-term institutions: speaking about care. Interface - Comunic., Saude, Educ., v.14, n.33, p.359-69, abr./jun. 2010.

This was an ethnographic investigation that had the aim of discussing the care provided for elderly people living in longterm institutions. The methodology consisted of conducting an interview with an elderly woman to reconstruct her life story, combined with systematic observation of the location. The analysis on the empirical data started with identification of topics of relevance to the narrator. These were worked up using care-related categories and were discussed through subcategories: self-care, informal care, charitable care and professional care. The results indicated that the care provided by professionals to elderly people do not always correspond to what is expected. We emphasize the importance of broadening the discussion on longterm institutions and the concept of care, taking into account the sociability of the elderly and promoting their health.

Keywords: Elderly people. Homes for the aged. Care. Caregiver. Old people's home.
Trata-se de pesquisa de cunho etnográfico que teve o objetivo de discutir o cuidado dispensado ao idoso que reside em instituição de longa permanência. A metodologia consistiu na realização de entrevista com uma idosa para a reconstrução da sua história de vida, aliada à observação sistemática no local. A análise do material empírico deu-se a partir da identificação de temas relevantes para o narrador, trabalhados por meio das categorias relativas ao cuidado, discutidas por meio de subcategorias: o autocuidado, o cuidado informal, o cuidado como caridade e o cuidado profissional. Os resultados indicaram que os cuidados prestados pelos profissionais, aos idosos, nem sempre correspondem ao que é deles esperado. Ressaltamos a importância de ampliar a discussão sobre instituições de longa permanência e o conceito de cuidado, levando em conta a sociabilidade do idoso e a promoção da sua saúde.

Palavras-chave: Idosos. Instituições de longa permanência para idosos. Cuidado. Cuidador. Asilo.

\footnotetext{
1 Instituto de Saúde Coletiva, Universidade Federal da Bahia (ISC/UFBA). Rua Barros Falcão, 463, Condomínio Palazzo Vaticano, Edifício Basílica São Pedro, apto. 4. Matatu/ Brotas, Salvador, BA, Brasil. 40.255-370. advssa@ufba.br
} ${ }^{2}$ ISC/UFBA. 
IDOSOS EM INSTITUIÇÕES DE LONGA PERMANÊNCIA...

\section{Introdução}

As instituições de longa permanência para idosos (ILPIs) são locais privilegiados para se observar esse modo de viver a velhice. Esse cenário, repleto de diferentes histórias de vida, é marcado por impressões negativas e positivas, sobre o significado de ser idoso. A solidão, o desprezo e o abandono são os primeiros pensamentos para justificar o porquê de uma pessoa idosa viver nessas instituições. $O$ conceito sobre tais instituições passa por uma ideia de "depósito de idosos" e foi construído através da concepção de que, nesse cenário, há solitários, ociosos e pessoas sem laços familiares ou de qualquer natureza. Essa maneira de pensar não é apenas "coisa" advinda do senso comum, pois, conforme afirma Scharfstein (2006), morar fora do contexto familiar, em uma instituição, pode gerar sentimentos de desamparo e abandono.

Essa percepção, cheia de estigmas e preconceitos, vem, aos poucos, sendo questionada, e já podemos pensar em outro perfil de residentes nas ILPIs. Ou seja, aqueles que, embora possuam família, preferem viver em uma instituição para idosos, alegando motivos variados, como: ser viúvo, não ter filhos, preferir ser independente, em lugar de incomodar filhos e netos; não conseguir bom entendimento com empregados, no papel de cuidadores informais; temer maus-tratos familiares, entre outros.

Dessa maneira, ao longo dos tempos, foi-se modificando o perfil do idoso institucionalizado e, conforme menciona Vieira (2003), a instituição de longa permanência não deveria ser configurada apenas como um local que acolhe idosos rejeitados ou abandonados pela família, mas, ser lembrada, compreendida e respeitada como uma escolha no contexto da vida de cada indivíduo, que busca a inserção em um grupo que o estimule para a construção de nova identidade, permitindo a sensação de pertencimento.

Por tudo isso, para entender como vivem idosos nesses locais, é preciso despir-se do preconceito, deixando o olhar fluir pelos espaços institucionais e, em pouco tempo, perceber que o ambiente da instituição nada tem de inerte, ocioso ou sem grandes acontecimentos. O dia-a-dia dos idosos continua repleto de tudo aquilo que se vê fora dos muros. Ou seja, existem conflitos, brigas, fofocas, competições, paixões, perdas e ganhos, apenas delimitados pelos muros e vigiados por quem assiste e cuida dos idosos.

Neste artigo, o cuidado é o foco do nosso olhar, ao observarmos os idosos em instituição de longa permanência; e, para a discussão, vamos explorar alguns enfoques teóricos. Efetivamente, existem várias perspectivas sobre o conceito de cuidar, um termo que, em nossa língua, tem muitos significados, demonstrando as múltiplas dimensões do cuidado. Para Heidegger (1989), o cuidar está em toda atitude do ser humano e faz parte da sua existência. Boff (1999) comenta que o discurso de Heidegger (1989) refere que o cuidado está na raiz primeira do ser humano, antes que ele faça qualquer coisa. E, se fizer, sempre estará imbuído de cuidado, pois ele é um modo de ser essencial, está sempre presente e é irredutível a qualquer outra situação anterior. Refere-se ao cuidado como uma necessidade de todo ser, o qual, sem cuidado, deixa de ser humano. "Se não receber cuidado, desde o nascimento até a morte, o ser humano desestrutura-se, definha, perde o sentido e morre. Se, ao largo da vida, não fizer com cuidado tudo que empreender, acabará por prejudicar a si mesmo e destruir o que estiver a sua volta" (Boff, 1999, p.34).

Não nos cabe, neste trabalho, entrar no debate filosófico e teológico, mas, trazê-lo como referência para discussão, pois o cuidado com pessoas idosas não poderia deixar de ter ou de ser um modo ético de pensar no outro. Dessa maneira, com o objetivo de discutir o cuidado prestado ao idoso, questionamos: como se configura o cuidado ao idoso em uma instituição de longa permanência?

Assim, entendemos que problematizar os modos de cuidado existentes em uma instituição para idosos, pode ajudar a construção de ILPIs de qualidade, tendo como resultados idosos saudáveis e com autonomia para o seu próprio cuidar. 


\section{Metodologia}

Este é um trabalho de natureza etnográfica, que compreende o estudo, pela observação direta e, por um período de tempo prolongado, das formas costumeiras de viver de um grupo particular de pessoas, associadas de alguma maneira, em uma unidade social representativa.

Desse modo, o estudo foi realizado em uma ILPIs filantrópica, mas que admite, também, idosos que possuem melhor condição social, situada na cidade de Salvador, Bahia, na qual fizemos observações sistemáticas por um período de 12 meses, em dois turnos semanais e cinco encontros, para a realização das entrevistas com uma das suas residentes, para a reconstrução da sua história de vida. O fio condutor da história de vida dessa idosa teve, como ênfase principal, a sua decisão de ir morar na instituição e a vivência nesse espaço. Seguiu-se um roteiro de perguntas, que facilitou a construção dessa trajetória. Nos encontros, a entrevista sempre foi iniciada de forma livre.

Nossa entrevistada encontrava-se orientada, lúcida e concordou em participar das entrevistas com cordialidade, assinando o termo de consentimento livre e esclarecido, com base na Resolução 196/96 do Conselho Nacional de Saúde (CNS), por meio da qual consideramos os princípios éticos que regem as pesquisas envolvendo seres humanos como: ponderação sobre os riscos e benefícios, tanto os atuais quanto os potenciais, individuais ou coletivos; garantia de que os danos previsíveis serão evitados, a relevância social da pesquisa e as vantagens para os sujeitos. Além disso, o projeto da pesquisa foi avaliado pelo Comitê de Ética em Pesquisa do Instituto de Saúde Coletiva da Universidade Federal da Bahia, por meio do parecer n.026-07/CEP-ISC, sendo aprovado em 12/07/2007.

Também, por questões éticas, a entrevistada está identificada pelo pseudônimo de Antonia, e suas narrativas foram analisadas a partir de expressões, frases ou enunciados, sendo consideradas em função da sua situação, no contexto da comunicação, e em relação a outros elementos estruturais.

A nossa categoria central, o cuidado, foi segmentada em subcategorias, a exemplo do autocuidado, o cuidado informal, o cuidado como caridade e o cuidado profissional.

\section{Resultados e discussão}

\section{Caracterização da instituição}

Essa instituição conta hoje com um número aproximado de 258 idosos, sendo que destes, 189 são mulheres e 69 homens. Esse número é variável, pois há constantes entradas e saídas de idosos, quer seja por não adaptação às normas da instituição ou por óbito. Os residentes têm idades que variam entre os chamados idosos jovens de sessenta a 75 anos, idosos acima de 75 anos, e os mais velhos, acima de oitenta anos. São viúvas(os), solteiras(os) ou separadas(os) em sua maioria, tendo uma pequena proporção de casais.

A instituição é composta por dez pavilhões, distribuídos entre: pavilhão coletivo para homens e para mulheres, pousadas, pensionatos e um pavilhão de repouso. Além disso, conta com um refeitório que serve aos pavilhões coletivos. Em cada pousada ou pensionato há uma copa e cozinha. $O$ alojamento está distribuído de acordo com a condição social a que o idoso pertence, sendo que o valor mensal a ser pago varia de acordo com a estrutura de cada alojamento. A diretoria é eleita periodicamente e existe um Conselho interno para discussão das situações da instituição, sendo que os idosos não possuem representação nessa instância. O serviço social conta com duas assistentes sociais, que se dividem entre o período da manhã e da tarde.

Os pavilhões, pousadas e pensionatos ficam sob a responsabilidade de supervisoras, que são técnicas de enfermagem e, ainda, são coordenados por "encarregadas" para os pavilhões coletivos femininos e para os masculinos - essas funcionárias organizam e supervisionam o cuidado prestado pelas(os) cuidadoras (es). Para o cuidado direto ao idoso, existe, em média, o número de dois a três cuidadores para atenderem a todos os idosos de um pavilhão coletivo. Para trabalhar junto às mulheres idosas são contratadas cuidadoras, enquanto os cuidadores atuam nos pavilhões masculinos. Nos pensionatos e pousadas, as cuidadoras permanecem durante o dia, ficando os idosos, à noite, apenas com o suporte 
da supervisora desse turno. Os profissionais são, também, técnicos de enfermagem, porém na instituição têm a função de cuidadores e percebem, pelo seu trabalho, o que corresponde a um saláriomínimo. Além disso, há idosos que podem pagar para dispor de cuidadores formais, cuja responsabilidade pela escolha e remuneração é dos familiares. A atividade de cuidador de idosos foi recentemente classificada como ocupação pelo Ministério do Trabalho e Emprego (TEM), passando a constar na tabela de Classificação Brasileira de Ocupações (CBO), sob o código 5162-10 (Souza, 2008).

O pavilhão de repouso recebe idosos que têm problemas de saúde e precisam de maiores cuidados; nele observamos a presença de duas enfermeiras, que se revezam entre os turnos matutino e vespertino, e de três a quatro técnicos de enfermagem, que cumprem escala de trabalho como se estivessem em uma unidade hospitalar. Além desses profissionais, mais diretamente ligados ao cuidado com a saúde do idoso, encontramos outros que ficam responsáveis por funções administrativas, funcionários da limpeza, vigilantes, e aquelas que trabalham na cozinha e na lavanderia.

Os médicos são clínicos e atendem no período da manhã, ficando de sobreaviso caso haja alguma intercorrência. Existem, ainda, dois médicos que são voluntários, sendo que um deles é geriatra. Em caso de emergência é acionado o serviço de ambulância. As enfermeiras permanecem na instituição todos os dias, exceto aos domingos. Os fisioterapeutas, a psicóloga, as terapeutas ocupacionais e a odontóloga atendem todos os dias.

O cuidado prestado aos idosos no asilo é realizado por meio de ações como: higiene (banho de idosos dependentes, auxílio ou ajuda a idosos parcialmente dependentes, troca de fraldas), prescrição e administração de medicações, alimentação, apoio e auxílio nas atividades de lazer e, sobretudo, na observação da evolução das condições de bem-estar dos idosos. O fato de estarem no confinamento da instituição, e sem a presença da família, pode deprimir os idosos, e evoluir com prognóstico não de um envelhecimento ativo, mas de uma velhice sombria.

A concepção do cuidado, por parte dos profissionais de saúde, é equivalente a uma ação técnica e mecânica. Por isso, notamos o despreparo para cuidar do idoso. Quando isso acontece, notadamente, traz o olhar reducionista para uma ação humana, que é intrínseca a qualquer indivíduo.

Percebemos, durante a pesquisa de campo, que a relação entre os profissionais e os idosos são construídas por uma série de conflitos, e a postura de alguns desses profissionais, para com os idosos, passa pelo questionamento e, algumas vezes, pela afirmação de que os idosos da instituição são desorientados, estão caducando, são briguentos e difíceis de lidar. Golfman (1999) comenta que, em instituições totais, existem estereótipos formados em relação aos internos e desses para com os funcionários e dirigentes da instituição.

Assim, em qualquer contato entre humanos há relações de poder, e isso também está presente quando se cuida ou se é cuidado. Geralmente, o cuidador é quem mais está investido de poder. Ou seja, parece que em suas mãos está a decisão do cuidado, porém também o ser, objeto do cuidado, emite sinais de poder rejeitando ou não colaborando com o cuidador. Pires (2005) aborda o cuidado como uma ação de ajuda e refere que, certamente, o poder está envolvido nessa relação, mas que "como todo o poder que se preza em manter-se forte, a ajuda atua por mecanismos camuflatórios, lançando mão de apelos pretensamente morais, para consolidar sua hegemonia" (p.732).

Destacamos que cuidador é a pessoa que oferece cuidados para suprir a incapacidade funcional, temporária ou definitiva. O cuidador pode ser formal ou informal. Ainda é importante ressaltar que, em uma perspectiva mais ampla do cuidado, o papel do cuidador ultrapassa o simples acompanhamento de atividades diárias e que não fazem parte da sua rotina, técnicas e procedimentos identificados como profissões legalmente estabelecidas, particularmente, na área da enfermagem (Brasil, 2008). A figura do cuidador já é assimilada, nos países desenvolvidos, como um parceiro da equipe de saúde, mas isso não acontece no Brasil, efetivamente, apesar de existir na Política Nacional de Saúde do Idoso (Brasil, 1997), regulamentada pela Portaria n. 1.395, de dezembro de 1999, tendo ênfase na importância de se estabelecer uma parceria entre profissionais de saúde e cuidadores informais. Grundy (1998) comenta que, na Inglaterra, estima-se que mais de seis milhões de pessoas sejam cuidadoras de indivíduos dependentes, em sua maioria, idosos. 


\section{A responsabilidade pela sua própria velhice}

Durante muito tempo pensou-se na velhice como uma fase de dependência, em que o indivíduo sempre deve esperar por outra pessoa para realizar suas atividades cotidianas, como se ser idoso fosse sinônimo de ser incapaz. Hoje, a concepção de ser idoso tem sido ampliada. Antes, ao se ter sessenta anos, já se estava fora do mercado de trabalho e da vida social; atualmente, a pessoa nessa faixa etária encontra-se em pleno vigor, trabalhando, saindo, relacionando-se e continuando a viver.

Desse modo, o incentivo ao envelhecimento ativo, particip-ativo, tomando decisões acerca das suas necessidades, é a grande chamada para se ser idoso e ter qualidade de vida, o que vale, sobretudo, para aqueles mais idosos, que, por algumas limitações, não podem usufruir dos prazeres da vida.

De um lado, imaginamos que a busca pelo envelhecimento ativo tende a camuflar a realidade da velhice. Mas, de outro, pensamos que deixar o idoso à espera pela responsabilidade da própria vida não irá proporcionar nenhum benefício para ele, nem para aqueles que estão à sua volta. No entanto, é válido incentivar essa autonomia, lembrando sempre e considerando as limitações que o envelhecimento provoca. Dessa maneira, Camarano (2006) comenta que, em 2003, existiam no País, aproximadamente, dois milhões de idosos com dificuldades para a realização de suas atividades da vida diária (AVD), e que cerca de cem mil residiam em instituições, porém nem todos tinham a autonomia comprometida.

Nossa entrevistada relatou-nos que chegou à instituição sem nenhuma dependência e, hoje, devido a uma queda que levou, depende de outras pessoas para realizar algumas atividades, sobretudo deambular.

A queda é uma das maiores causas de mortalidade e morbidade entre os mais idosos e precisa ser observada nas instituições de longa permanência, por meio de medidas de proteção, promoção e de reabilitação ao idoso, quando vítima desse tipo de intercorrência. Assim, ela é um evento real na vida de idosos, e provoca consequências muitas vezes irreparáveis. Dessa maneira, o idoso vítima de queda deve ser avaliado de forma ampla e integral (Fabrício, Rodrigues, Costa Junior, 2004).

Ao falar sobre cuidado, a idosa voltou ao passado, destacando o autocuidado e a autonomia, e não esquecendo de revelar que também recebia cuidado:

"A minha madrinha me trazia num luxo de gente rica igual a ela, porque ela era de uma família muito rica, me trazia num luxo! Então até hoje eu gosto de andar arrumada".

$\mathrm{Na}$ instituição do estudo, estar sempre arrumada provoca nas outras idosas uma espécie de competição, é isso que nos afirma a senhora Antonia:

“Elas não gostam não. Chamam-me de metida a rica, assim, me tratam com muita diferença, porque eu meço muita distância dela".

Assim, vão se constituindo as relações entre os idosos residentes, como que reproduzindo o que está externo aos muros da instituição. A competição entre eles é uma constante, gerando até mesmo intrigas, brigas e, por que não dizer, agressões. Competem pelas novas amizades que fazem, pelos objetos que possuem, enfim, pela melhor velhice:

"Aquela que vai ali já caiu três vezes, você acha que aquela idosa ali está mais velha do que eu?"

Por outro lado, para os idosos, até mesmo o ato de se cuidar pode ser visto como impróprio ou com um sentido pejorativo, ligado às questões de namoro e sexo. O gostar de roupas e acessórios, que são normalmente usados pelos mais jovens, garante ao idoso o título de ridículo:

"Quando eu era jovem eu me cuidava muito depilava a sobrancelha, usava batom, me pintava que naquele tempo usava rouge. Antes eu estava jovem e hoje eu estou mais velha e acho ridículo uma velha pintada!. Nunca usei calça porque eu não gostava, no colégio eu 
IDOSOS EM INSTITUIÇÕES DE LONGA PERMANÊNCIA...

usava saia e hoje pior. Vestido de alça eu nunca usei. Aqui tinha uma velha que se pintava eu acho feio vestido de alça eu acho feio, usa quem gosta, não é?"

O vestuário e o cuidado com a aparência é uma questão que passa pelo sentido de geração, pelo contexto histórico, existindo, também, relação com a posição social dos indivíduos. Quanto a isso, não está prescrito para nenhum idoso o que é certo ou errado, podendo sentir o desejo de seguir o que a nova geração usa ou manter o que fez parte de sua história. No entanto, o preconceito existe entre eles. A moda para os idosos vem acompanhando a tendência atual, e o estilo individual e particular de cada um é que define o que eles/elas usam e como se vestem.

A senhora Antonia relata que se cuida e, em sua fala, é notado que o cuidado a que se refere é apenas corporal:

“Eu me cuido, tomo meu banho, penteio meu cabelo e agora mesmo está precisando cortar; pinto minha unha. Uso o sabonete que eu gosto que é bom para a pele".

Lembramos que o autocuidado vai além da aparência, mas é por ela onde tudo começa, pois, ao vermos alguém que apresenta desleixo em relação ao seu corpo, certamente essa característica estará presente nos diversos aspectos da vida.

Dona Antonia não demonstra cuidar de seu "quarto". Nos pavilhões coletivos, os quartos configuram um espaço com seis camas, separadas por um pequeno armário de alvenaria. Os pensionatos possuem configuração diferente, são pequenos vãos, contendo cama, armário, cômoda ou outros móveis trazidos pelos internos, e são fechados por uma porta sanfonada. As pousadas constituem-se de uma suíte, de tamanho maior, com privacidade, fechada com porta de madeira. Sempre, em nossos encontros, observamos que o "quarto", ou melhor, a cama de Dona Antonia estava desarrumada, com muitas roupas espalhadas, vasilhas, latas e frutas em meio aos retratos por sobre o armário. O odor forte era de roupa suja, urina e mofo. Ela pendurava as roupas e calcinhas em um acessório acima de sua cama.

Em uma de nossas visitas, a coordenadora do pavilhão reclamou com ela e disse-lhe que não poderia pendurar roupas na cama, e que devia arrumar melhor seu leito. Dona Antonia não deu atenção, apenas comentou que as calcinhas eram colocadas em um varal fora do pavilhão, e que frequentemente desapareciam. Assim, ela preferia deixá-las acima de sua cama.

Viver no pavilhão coletivo da instituição em estudo é viver sem muitos privilégios. Os espaços são pequenos e o aglomerado leva à falta de privacidade, prejudicando o cuidado. Uma das funcionárias do serviço social da instituição referiu que é difícil lidar com isso, pois muitos idosos não compreendem a importância da higiene. Por outro lado, os idosos informaram que estão sendo impedidos de ter objetos, roupas e alimentos, e por isso não seguiam algumas regras importantes para o convívio coletivo.

Nesse sentido, privar o idoso de ter um pedaço da sua história, anterior à entrada na instituição, por meio da guarda dos seus pertences, leva-nos a refletir como o envelhecer, para alguns idosos, é marcado pela perda de espaços, pessoas, objetos, bens, privacidade e individualidade, o que certamente, poderá afetar o autocuidado. No entanto, Camarano (2006) refere que dados epidemiológicos demonstram que a maioria dos idosos não deixa de se mobilizar para as atividades básicas do dia-a-dia, preservando fortemente sua autonomia e autocuidado.

\section{O cuidado esperado e o cuidado realizado}

Falar sobre a velhice remete a algumas questões sociais. Abordaremos as relacionadas às dificuldades das famílias em lidarem e cuidarem de seus idosos, o que não significa dizer que o mais importante é discutir as dificuldades do envelhecimento, enfocando apenas suas consequências biológicas, como limitações e aparecimento de doenças, entre outras. Nesse contexto, destacamos a importância de discutir o cuidado que é esperado pelos idosos, como responsabilidade familiar e institucional e, por que não dizer, um ato de solidariedade de seus familiares? Em nossa legislação relativa à proteção dos idosos, o Estado afirma ser da família o dever de zelar e assistir às necessidades que a velhice impõe. Porém, no momento atual, parece-nos impossível deixar apenas para as famílias a missão de cuidar. 
É necessário haver uma rede de apoio interligada: o Estado, a família e a sociedade, para que o cuidado deixe de ser uma mera ação pontual e técnica. A integração dessas esferas, cada uma com o seu limite de atuação, sem dúvida, estaria contribuindo para a melhoria da qualidade de vida dos idosos e das relações entre as gerações.

Por outro lado, não é possível negar a carga negativa do envelhecimento, uma vez que, mesmo as pessoas que estejam envelhecendo, de maneira primária ou fisiológica, podem experimentar alterações físicas em órgãos como a visão, a audição ou de outros aparelhos, como o locomotor, por exemplo.

Nesse sentido, faz-se necessário falar das perdas físicas provocadas pelos anos vividos e da família. As famílias alegam não terem condições para prover o sustento da velhice. Além disso, existem as transformações que a instituição familiar tem vivenciado. Anteriormente, competia apenas à mulher o cuidado com os filhos. Como as mulheres estão participando mais do mercado de trabalho, espera-se que o cuidado com os pais idosos seja compartilhado entre os filhos, independente do gênero.

Karsch (2003) afirma que, no Brasil, mesmo nas famílias de renda inferior a dois salários-mínimos, a opção de colocar o idoso em ILPIs acontece somente no limite de elas oferecerem os cuidados necessários. Isso ocorre, sobretudo, porque o cuidado diário e permanente ao idoso dependente provoca perturbações, que afetam a vida familiar (Kawasaki, Diogo, 2001).

Ser idoso e não ter ninguém do seu ciclo de relacionamento familiar é o mesmo que não ter cuidado. Equivale a não ter quem se responsabilize pelo suprimento de suas necessidades humanas básicas, como: alimentação e segurança, entre outras. Tal situação é relatada como algo "pesado". Estar em uma instituição asilar, sem ter família, faz com que o idoso viva esperando o divino, que Deus o ajude!

$\mathrm{Na}$ história de vida de dona Antonia sua fala está carregada de conotações negativas sobre a velhice. Podemos mesmo afirmar que ela vê o lado "pesado" de ser idosa e enfatiza as consequências disso para si:

\begin{abstract}
"A velhice é uma tristeza. A velhice minha filha, eu vejo a velhice aqui, cada pesada, aquela mesmo é uma velhice pesada. Oh coitada! Oh minha filha! Porque não tem ninguém assim, né? Como eu não tenho, mas eu tenho a Jesus e tem essa menina que Jesus me colocou na frente e faz minhas coisas, né?"
\end{abstract}

Quem se responsabiliza pelo cuidado com dona Antonia? Se ela não tem mais filhos, e as netas não aparecem para visitá-la? Na instituição asilar em estudo, o cuidado é algo realizado de duas maneiras: o cuidado relacionado ao ato de caridade, geralmente realizado por voluntários ou religiosos, pois a instituição teve sua origem no acolhimento de mendigos que não possuíam família e viviam pelas ruas; e o cuidado dispensado como uma ação profissional, realizado por funcionários remunerados pelo asilo, dentre eles: médicos, enfermeiras, odontóloga, assistentes sociais, nutricionista, fisioterapeutas, terapeutas ocupacionais, psicóloga e técnicas de enfermagem, além de cuidadores contratados pelas famílias para cuidar do idoso. Essas formas de cuidar podem estar interligadas ou não, a depender do indivíduo que presta e recebe o cuidado.

Entretanto, é importante referir outro tipo de cuidado denominado de cuidado informal, que se traduz na necessidade e na busca de alguém que assuma a função de cuidador - e a família seria, pelos laços afetivos e de sangue, quem mais se adequaria a essa função. Essa pessoa, deveria prestar o cuidado sem cobrar nada em troca, apenas pela solidariedade e empatia com a velhice. Camarano e Pasinato (2004) apontam que, apesar de ser o ambiente familiar o mais adequado para o bem-estar do idoso, existe a necessidade de se estabelecerem políticas públicas que possibilitem a modalidade de atendimento institucional para determinados idosos.

Nos casos em que a família está ausente, a dependência do cuidado profissional ou de cuidadores formais faz os idosos lamentarem a velhice e a sua ida para a instituição. Estar em meio à família, aos filhos, que um dia teve, mas que, por força da vida perdeu, leva ao que Attias Donfit (1988) coloca como parte dos acontecimentos do curso da vida, o que remete o idoso às recordações do passado, da juventude e da vida entre os parentes e amigos, tudo isso para fugir do viver na solidão, algo que é sentido como um forte contraste.

O não saber o que pode lhes acontecer ao precisarem de ajuda, de cuidado é motivo de preocupação das pessoas idosas; e, logo, parece que atrelado a isso vêm as possibilidades de 
IDOSOS EM INSTITUIÇÕES DE LONGA PERMANÊNCIA...

acontecerem maus-tratos, em decorrência da falta ou negligência na prestação desse cuidado. Antonia refere-se a isso, quando comentou que:

"Eu imagino quando eu ficar mais velha aqui, adoecer, porque na velhice você pode ser bem tratada ou maltratada, quem sabe é Jesus. Então eu entrego muito a Jesus".

Em sua fala, Antonia deixa escapar o sentimento da fé e da necessidade de se apegar ao divino, para diminuir sua angústia de viver em ILPIs.

Desvinculando a solidariedade de ser apenas um ato de caridade, procuramos analisar o conceito segundo o que ocorre entre pessoas que possuem laços de parentescos. Nesse sentido, Durkheim (2000) referiu que a solidariedade social, a qual está correlacionada à ideia de ligação familiar, trata a família como uma microssociedade. Nela, podem ser observados os modos de constituição, integração e interação, através, até mesmo, da divisão do trabalho, de acordo com a idade e o sexo.

Ao relacionar a solidariedade com um sistema de trocas entre as gerações, Mauss (1988) referiu que a primeira tem sentido quando a desvinculamos da dívida, que circula entre as gerações. Dessa maneira, compreendemos que tudo o que os pais fizeram para seus filhos torna-se dívida que estes têm para com eles. Assim, o que se espera dos filhos é que eles retribuam, quando seus pais estiverem idosos e dependentes de cuidado.

A caridade não está imbuída pela responsabilidade com a vida do outro mas por uma ideologia, na maioria das vezes, cristã, envolvendo crença de espiritualidade, pelo desejo de ser reconhecido ou por esperar que fazendo o bem, também receberá o mesmo. Pode ser vista como um ato de solidariedade ou de misericórdia, ao encontrar pessoas abandonadas, precisando de afeto, alimentos ou com quaisquer outras necessidades.

$\mathrm{Na}$ instituição de longa permanência, o cuidado como caridade é prestado pela presença, sobretudo, da igreja católica, que está na instituição desde sua origem. Observamos, também, voluntários que prestam cuidado espiritual aos idosos, levando-os às missas que são realizadas na instituição ou realizando atividades, como leituras da bíblia e visitas aos pavilhões, dando panfletos e falando de Deus.

\section{Em busca de novos cuidadores}

Viver em uma instituição para idosos sem ter o que, durante muito tempo, Ihe foi familiar, como o trabalho, os amigos, a família, é muitas vezes um exercício para a (re)construção de uma história diferente. Freire Júnior e Tavares $(2004,2005)$ referem que idosos residentes em ILPIs, por estarem afastados do ambiente em que construíram suas vidas, têm saudades e desejos, advindos da exclusão e da limitação de viverem uma nova situação.

Quando jovens, comumente, pensamos que tudo relacionado à vida familiar está garantido. Para isso, basta casar, ter filhos, ter uma casa, uma aposentadoria e a velhice será tranquila, sem muitas novidades, apenas as esperadas, como algumas doenças e limitações que "todo idoso tem".

Passam-se os anos e algumas adversidades inesperadas acontecem: mortes de entes queridos, que pareciam jovens e com muita saúde e, portanto, são eventos não programados para acontecer, pois, sabe-se, ou pelo menos se pensa, que o correto é os idosos morrerem antes dos jovens, ou os pais antes dos filhos. Mas isso não se encontra prescrito em nenhum manual de trajetória de vida. As intercorrências causam desânimo, e o que fazer da vida, se o que foi planejado não pode mais acontecer? Os filhos não podem ou não tomam conta dos pais já idosos, e os contemporâneos já não mais estão vivos e tudo parece "novo".

Esse "novo" não significa sempre algo de "bom", mas, sim, alguma coisa que impulsiona o indivíduo para reescrever sua história com outros personagens e se adaptar a outros cenários. É assim que vemos os idosos que residem em instituições de longa permanência, estão a todo instante reescrevendo sua história de vida e perguntando o porquê de estarem ali. Alguns referem ter ido por vontade própria, mas essa vontade está envolvida por alguma situação em que se percebe que já não há entendimento ou solidariedade entre as gerações: 
"[...] eu quis vir para aqui, eu mesma que quis vir porque eu morava com uma neta. A neta mais velha, ela era boazinha, ainda é, agora eu não sei porque ela não está aparecendo, ela é casada tem um filho que Deus levou num desastre, esse tenho muita saudade dele, o menino era tão apegado a mim. Ele dizia porque você vai Antonia? Oh meu filho, eu vou embora. Mas a avó dele é sergipana é muito grossa, eu fiquei com medo dela me maltratar".

Essa fala de dona Antonia mostra que as relações familiares são o "pano de fundo" para entendermos o porquê de idosos viverem em ILPIs. No caso de Antonia, existe um conflito, sobretudo, entre ela e sua nora, a qual ela denomina de "sergipana", para justificar seu comportamento agressivo e grosseiro, chegando a levantar a possibilidade de ocorrerem - se é que já não tenham ocorrido maus-tratos. Nesse sentido, a instituição passa a ser uma opção para sobreviver com segurança.

Assim, nessa nova vida na instituição, outros laços vão se construindo. Foi assim que aconteceu com a senhora Antonia, proveniente de uma família com dez irmãos, que, ao se casar, teve oitos filhos, e hoje vive na ILP, sem ter a visita de nenhum familiar. Possui três netas, mas elas não aparecem desde sua ida para a instituição. Os profissionais que trabalham no pavilhão, onde D. Antonia reside, dizem que nenhum familiar vem procurá-la, apenas uns seminaristas visitam a idosa, aos domingos. Sobre eles, a idosa referiu:

"Agora eu sinto falta de receber visita, só os seminaristas não deixam de vir aqui, todo domingo eles estão aqui".

O desejo de ser visitada e lembrada faz a idosa emocionar-se quando fala dos seminaristas:

"Os seminaristas são estrangeiros, esses meninos me traziam assim na palma da mão e eu me apeguei tanto a eles, espiritual, viu? Que é uns meninos que me respeitou muito, viu, hoje tem um que é padre lá na Argentina e me escreve. Para esses meninos eu rezo muito".

Dona Antonia demonstrou sentir falta de alguém que lhe seja próximo, um cuidador, um amigo. Assim, outra idosa, quando passava pelo pavilhão observando nossa entrevista, perguntou: "Camarada, né?", a senhora Antonia respondeu: "graças a Deus, eu tenho muita!".

É o desejo também de demonstrar que tem pessoas que se preocupam e cuidam dela. Antonia mostrou fotos tiradas com voluntários que vão à instituição, cartas de estagiários da terapia e dos seminaristas. Essas demonstrações de afeto deixavam-na muito feliz, apesar de dizer:

“Esses meninos, os seminaristas que estão aí, vivos, são umas pessoas lindas, mas eu digo toda hora: oh meu Deus! será que algum dia esses meninos vão esquecer que eu existo? Mas eu acho que não esquecem não!"

A busca de Antonia por novos cuidadores na instituição é marcante e ela se apega a um pequeno estoque de lembranças por meio das cartas recebidas e das fotos, ou ainda mantém contatos, mesmo à distância, através de telefonemas, além da esperança de que alguém ainda apareça para visitá-la. Para Waldow (2001, p.129), "o cuidado humano consiste em uma forma de viver, de ser, de se expressar. Uma postura ética e estética frente ao mundo".

O abandono dos familiares remanescentes é uma realidade na vida dessa idosa e, por isso, ela teme ser esquecida e ter de começar tudo de "novo", ou seja, fazer novos amigos, buscar novos cuidadores. Nesse sentido, o cuidado deixa de ser algo "especializado", realizado na ação de administrar medicações, dar alimentação, fazer a higiene, e passa a ser "algo" especial, uma ação social com pequenas demonstrações de sentimentos positivos. 
IDOSOS EM INSTITUIÇÕES DE LONGA PERMANÊNCIA...

\section{Considerações finais}

Os resultados desse estudo indicaram que os cuidados prestados pelos profissionais, aos idosos, nem sempre correspondem ao que é deles esperado. Assim, ao concluiírmos este trabalho percebemos que, ainda, é necessário explorar mais o tema do idoso em instituição de longa permanência e o cuidado prestado a esse idoso. Estudos que abordem a forma de vida dessas pessoas são necessários e de grande importância para a construção de melhores alternativas para o atendimento e o cuidado.

A instituição de longa permanência não é um "depósito" para se guardar o idoso, é um lugar para se viver, e não é a instituição que irá responder pelos abandonos que existem, de modo generalizado. É preciso que fique claro que, independentemente da maneira como o idoso chegou à instituição, ele/ela precisa viver com dignidade, e, para isso, o Estado, a família e a sociedade também fazem parte da rede de cuidadores de um País que envelhece.

Dessa maneira, políticas públicas efetivas e realizáveis devem ser planejadas, destinadas ao apoio aos idosos sem família, ou ainda que tenham família, e esta não possa suprir suas necessidades de cuidados. Devem existir serviços sociais e de saúde que garantam o cuidado ao idoso, assegurando direitos de cidadania e promovendo a dignidade de envelhecer. Nesse sentido, ampliar o conceito de cuidado, vislumbrando-o como uma ação social solidária, e que é parte da sociabilidade dos indivíduos, significa um grande desafio para se repensarem os espaços de cuidado ao idoso, como as instituições de longa permanência.

\section{Colaboradores}

As autoras trabalharam juntas em todas as etapas da elaboração do manuscrito.

\section{Referências}

ATTIAS-DONFUT, C. Generations et ages de la vie. Paris: PUF, 1988.

BOFF, L. Saber cuidar: ética do humano - compaixão pela terra. Petrópolis: Vozes, 1999.

BRASIL. Ministério da Saúde. Secretaria de Atenção à Saúde. Secretaria de Gestão do Trabalho e da Educação na Saúde. Guia prático do cuidador. Brasília: Ministério da Saúde, 2008. Disponível em: <http://www.bvsms.saude.gov.br/bvs/publicaçoes/ guia_pratico_cuidador.pdf>. Acesso em: 28 out. 2009.

Ministério da Previdência e Assistência Social. Secretaria da Assistência Social. Lei n. 8.842, de 4 de janeiro de 1994. Dispõe sobre a Política Nacional do Idoso. Brasília, 1997.

CAMARANO, A.A. Mecanismos de proteção social para a população idosa brasileira. Rio de Janeiro: IPEA, 2006. (Texto para discussão, n.1179).

CAMARANO, A.A.; PASINATO, M.T. O envelhecimento populacional na agenda das políticas públicas. In: CAMARANO, A.A. (Org.). Os novos idosos brasileiros. Rio de Janeiro: IPEA, 2004. p.253-92.

DURKHEIM, E. Divisão do trabalho e suicídio. In: RODRIGUES, J.A. Sociologia. São Paulo: Ática, 2000. p.73-123.

FABRÍCIO, S.C.C.; RODRIGUES, R.A.P.; COSTA JÚNIOR, M.L. Causas e consequências de quedas em idosos atendidos em hospital público. Rev. Saude Publica, v.38, n.1, p.93-9, 2004. 
FREIRE JÚNIOR, R.C.; TAVARES, M.F.L. A saúde sob o olhar do idoso institucionalizado: conhecendo e valorizando sua opinião. Interface - Comunic., Saude, Educ., v.9, n.16, p.147-58, 2004-2005.

GOFFMAN, E. Manicômios, prisões e conventos. 6.ed. São Paulo: Perspectiva, 1999.

GRUNDY, E. The epidemiology of aging. In: TALLIS, R.C.; FILLIT, H.M. (Eds.). Brocklehurst's textbook of geriatric medicine and gerontology. London: Churchill Livingstone, 1998. p.1-18.

HEIDEGGER, M. Ser e tempo. Petrópolis: Vozes, 1989.

KARSCH, U. Idosos dependentes: famílias e cuidadores. Cad. Saude Publica, v.19, n.3, p.861-6, 2003.

KAWASAKI, K.; DIOGO, M.J.D. Assistência de enfermagem ao idoso: perfil do cuidador formal - parte I. Rev. Esc. Enferm. USP, v.35, n.3, p.257-64, 2001.

MAUSS, M. Ensaios sobre a dádiva. Lisboa: Edições 70, 1988.

PIRES, M.R.G.M. Politicidade do cuidado como referência emancipatória para a enfermagem: conhecer para cuidar melhor, cuidar para confrontar, cuidar para emancipar. Rev. Latino-am. Enferm., v.13, n.5, p.720-36, 2005.

SCHARFSTEIN, E.A. Instituições de longa permanência: uma alternativa de moradia para os idosos brasileiros na vida contemporânea. 2006. Tese (Doutorado) Universidade Federal do Rio de Janeiro, Rio de Janeiro. 2006.

SOUZA, M.R. Os direitos trabalhistas do cuidador formal da pessoa idosa. In: BORN, T. (Org.). Cuidar melhor e evitar a violência: manual do cuidador da pessoa Idosa. Brasília: Secretaria Especial dos Direitos Humanos, Subsecretaria de Promoção e Defesa dos Direitos Humanos, 2008. Disponível em: <http://www.ciape.org.br/ manual_cuidador.pdf>. Acesso em: 28 out. 2009.

VIEIRA, E.B. Instituições geriátricas: avanço ou retrocesso? Rio de Janeiro: Revinter, 2003.

WALDOW, V.R. Cuidado humano: o resgate necessário. 3.ed. Porto Alegre: Sagra Luzzatto, 2001.

FREITAS, A.V.S.; NORONHA, C.V. Ancianos en instituciones de larga permanencia: hablando de cuidado. Interface - Comunic., Saude, Educ., v.14, n.33, p.359-69, abr./jun. 2010.

Se trata de una investigación de tipo etnográfico que tuvo el objetivo de discutir el cuidado dispensado al anciano que reside en institución de larga permanencia. La metodología ha consistido en la realización de entrevista con una anciana para la reconstrucción de sua historia de vida, aliada a la observación sistemática en el local. El análisis del material empírico se da a partir de la identificación de temas relevantes para el narrador, trabajados por medio de las categorías relativas al cuidado discutidas por medio de sub-categorías: el auto-cuidado, el cuidado informal, el cuidado como caridad y el cuidado profesional. Los resultados indican que los cuidados prestados por los profesionales a los ancianos no siempre corresponden a lo que se espera de ellos. Resaltamos la importancia de ampliar la discusión sobre instituciones de larga permanencia y el concepto de cuidado, teniendo en cuenta la sociabilidad del anciano y la promoción de su salud.

Palabras clave: Ancianos. Hogares para ancianos. Cuidado. Cuidador. Asilo. 